\title{
Ideología y aculturación religiosa en una revista misionera del Perú del siglo XX
}

Artículos originales: ANTROPOLOGÍA

Recibido: 20/04/2021

Aprobado: $25 / 06 / 2021$

Publicado: 14/10/2021

\section{RESUMEN}

Este artículo analiza las principales ideas de la revista Misiones Dominicanas del Perú (MDP), que empezó a editarse en 1919. Su línea textual (y que incluyó profusamente la fotografía) nos muestra las herramientas conceptuales e ideológicas de un proceso particular de evangelización tardía en la selva sur del Perú. También muestra su empeño de construir con palabras e imágenes, una frontera civilizatoria en la cual estaba ausente el sujeto originario.

Palabras clave: evangelización tardía; Amazonía; misiones

\section{Ideology and religious acculturation in a 20th century Peruvian missionary magazine}

ABSTRACT

This article analyzes the main ideas from Misiones Dominicanas del Perú magazine, which publication began in 1919. Its text line (and that includes the photography profusely) shows us the conceptual and mental tools of a late evangelization process in the southern jungle of Perú. It also shows his determination to build with words and images a civilizing frontier in which the original subjects are absent.

KeYwords: Evangelization; narrative; Amazonia; missions 


\section{Introducción}

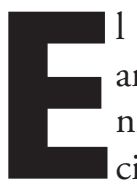
l presente artículo tiene como propósito, el análisis de una revista fundada por los dominicos en 1919 para dar cuenta de las incidencias de su proceso de evangelización tardía en las montañas tropicales del Cusco, entendiéndolas como un modelo de asimilación.

Si bien la presencia dominica en el Perú es tan temprana como la conquista española misma, es en este proceso que pueden constatarse ideas e imágenes que en parte estaban arraigadas para una región en crisis y, de las ideas de una orden religiosa que había renovado su arsenal misionero con sacerdotes españoles que poseían mentalidades y discursos que expresaban elocuentemente las del catolicismo peninsular. Cuando se releen las páginas de esta revista, pueden notarse ejes discursivos, que uno podría rememorar las antiguas campañas de extirpación de idolatrías que remecieron los Andes en el siglo XVII.

El objetivo es entonces, entender estos procesos de representación y categorización que guiaron estas acciones narradas en la revista mencionada. Finalmente, esperamos que este trabajo ayude a entender procesos de aculturación religiosa en una determinada sociedad. ${ }^{1}$

\section{El siglo XIX: la domesticación del espacio peruano por los religiosos}

En el llamado periodo tardío de la colonia (17001810), la iglesia y las misiones perdieron influencia por las circunstancias políticas e ideológicas del momento. La influencia de las ideas de la ilustración y la acción independentista, permitieron que sean otras las preocupaciones de los españoles. Por ejemplo, los inquisidores de México y Lima van pasando lentamente del castigo para delitos religiosos y sexuales a la censura política (Alberro, 1981; Palma, 1958 [1897]).

El Perú que nace con la independencia, hereda esa pugna entre liberales y católicos conservadores; en ese sentido la iglesia peruana no fue inmune al clima general. No sólo había escasísimos fondos como

1 Queremos agradecer al personal de las bibliotecas de la Pontificia Universidad Católica del Perú, del Instituto Riva-Agüero, la Universidad Nacional Mayor de San Marcos y, sobre todo, del Centro Cultural Pío Aza de la ciudad de Lima. producto de la desamortización y el encogimiento de sus rentas, sino que muchos sacerdotes se fueron del continente americano y las misiones prácticamente se paralizaron.

La Amazonia peruana si bien nominalmente fue heredada por el nuevo país republicano, se afianza su aislamiento (al igual que los Andes) respecto del litoral costeño y de la ciudad de Lima, que se constituye como el nuevo eje del poder.

Si bien jesuitas y franciscanos habían explorado ciertas zonas selváticas en el virreinato peruano desde sus sedes en Quito o Huánuco, su presencia simulaba una especie de archipiélago de la fe.

Por las condiciones existentes, la selva nunca tuvo la importancia que se le concedió a la sierra, donde los indios tributarios y la explotación minera fueron el clivaje de la economía colonial. En cambio, la comunicación selvática era sólo a través de los ríos y la importancia económica de su territorio fue casi nula. Viajes en lomo de mula y adentramientos peligrosos en la navegación fluvial, con el frecuente rechazo y ataques de la población originaria.

Posteriormente la leyenda mística de los franciscanos se trocará por el interés "científico» y de auscultación del territorio selvático de los ríos Chanchamayo, Perené, Mantaro y el Apurímac en el siglo XIX.

Fue una época que alguien ha llamado la «mirada liberal sobre el Oriente», que también fue el de la secularización de las misiones. Por ejemplo, ya en mayo de 1894, en una misiva a León XIII, por los obispos del Perú, se especula sobre las posibilidades de evangelización del «oriente peruano».

El 25 de diciembre de 1896, bajo la advocación de Francisco Solano, se acuerda apoyar las misiones a los «infieles» que en el Ucayali sostenían los franciscanos del convento de Ocopa «a fin de acelerar la conversión de tantos peruanos a la fe y la civilización» (Esponera y Lassegue, 1991: 56).

Entre 1898 y 1900 es una fecha importante para el brazo eclesial de un país que quería "domesticar y nacionalizar el suelo peruano", pues se crean las tres Prefecturas Apostólicas del Oriente. Entre ellas, la Prefectura de Santo Domingo de Urubamba (1900) y que luego se transformaría en el Vicariato Apostólico de Madre de Dios y Urubamba (1913) confiada a los dominicos de la provincia de España. Su primer prefecto apostólico sería fray Ramón Zubieta. En síntesis, ya a fines del siglo XIX, la iglesia católica volvió a 
ser de cierta manera, el elemento "cohesionador y homogeneizador» en aquellos lugares donde el Estado no podía o quería llegar. ${ }^{2}$

En ese sentido, Basadre diría que un acontecimiento fundamental del siglo XX será el crecimiento de «la imagen del indio» (Tord 1978). Nosotros podemos agregar que también fue el de la selva peruana, pues la conquista de la Amazonia sería una política sistemática de Estado, sobre todo a partir de 1950. Aunque con la estabilidad de mediados del siglo XIX, es que el Estado peruano patrocina las primeras exploraciones de la «montańa».

Latifundistas y militares, convertidos en autoridades políticas, planifican y emprenden viajes exploratorios para sopesar y cuantificar los recursos de esta inmensa región y ponerla en el carril del progreso y la civilización. Tenemos los casos del coronel del ejército Faustino Maldonado (1820-1861) muerto trágicamente explorando el río Madre de Dios y cuya aventura había empezado en Paucartambo (Cusco), el coronel Pedro Portillo veterano de la guerra con Chile y senador por Loreto, Manuel Antonio Mesones Muro (1862-1930) explorador del río Marañón. También a José Benigno Samanez Ocampo (1838-1887) un hacendado que explora los ríos Apurímac, Ene, Tambo, Urubamba y Ucayali entre 1883 y 1884.

En 1886, Carlos Fry parte del Cusco y recorre las «cabeceras del torrentoso Vilcanota, hasta la confluencia del majestuoso Ucayali con el Marañón, para formar al anchuroso Amazonas", sus descripciones son muy expresivas y se aferran a una fidelidad casi etnográfica «si algo he apuntado lo he visto» dirá (1889: 3). Aunque por lo general, en sus páginas la naturaleza lo absorbe todo, donde la disociación con los hombres de la tierra es notoria.

Aunque, en una parte se lamenta que los pocos misioneros de las zonas que atraviesa hayan incentivado en los salvajes un rechazo al progreso, es decir su temor a trabajar para los terratenientes y caucheros, entendidos estos últimos, como vehículos de la civilización.

2 Francisco Sales Soto crea las Prefecturas Apostólicas con una extensión de casi un millón de kilómetros cuadrados, donde el Estado peruano cede soberanía. Aparte de la asignada a los dominicos, se crearon las de San León de Amazonas en Iquitos y la de San Francisco de Ucayali cuyos misioneros provenían de Santa Rosa de Ocopa. La creación de este proyecto evangelizador fue alentada desde sus inicios (1900) por la Congregación de Propaganda Fide.
En 1867 se crea la Comisión Hidrográfica del Amazonas a cargo del Almirante Tucker. Para 1898 se promulga la Ley de Tierras de Montańa y en 1909 una nueva Ley General de Montaña. ${ }^{3}$

\subsection{Evangelización tardía}

Los trabajos sobre la evangelización en América son un terreno fértil y farragoso (Hampe, 1997). Cada orden religiosa comprometida tiene un texto emblemático o relevante (Esponera y Lassegue, 1991; Marzal y Negro, 1999; Richter, 1995). También existen trabajos que cruzan la evangelización con los aspectos económicos, culturales, legales u organizativos.

Dentro del tema que tratamos no son muy frecuentes los referidos a los mecanismos socioculturales o antropológicos de la conversión religiosa en contextos de evangelización, como pieza fundamental del colonialismo (Marzal, 1983; Hermosa, 1986; López de Carvalho, 2015).

Algunos de ellos han sido elaborados por antropólogos, aunque muchos lo hacen dentro de una óptica doctrinaria o para decirlo más claramente, usan la antropología para entender y justificar los mecanismos de conversión, tal como hicieran sus ancestros durante la colonización americana (siglos XVI al XVIII).

Aunque a partir de los años 60 del siglo XX, algunos se nutrieron de ideas renovadas de la teología de la liberación y de una iglesia que optaba por amoldarse a la cultura de las sociedades americanas en un continente plural y con profundas desigualdades socioeconómicas. (Marzal, 1991) ${ }^{4}$

La política colonial religiosa establecía que a la par de las reducciones, deberían constituirse "doctrinas indígenas» a cargo de un cura o párroco de indios, diestro en la «lengua natural de los ingas», cargo que era además muy solicitado pues les permitía un fácil enriquecimiento (Acosta, 2014). Los jesuitas rechazarían este modelo y optaron por el de las «reduc-

3 En 1894 Fitzcarrald rodeó una aldea maschco y estableció contacto. En 1940 los dominicos apoyan una expedición de la Wenner-Green en la que tuvieron una refriega con los amarakaeris.

4 Ya es clásica la siguiente fórmula de Marzal sobre la transformación religiosa colonial peruana: «Fue un proceso en parte aditivo, en parte sustitutivo y en parte de síntesis entre las creencias, ritos, las formas de organización y las normas éticas de los sistemas religiosos que se pusieron en contacto» (1983). Las investigaciones contemporáneas demostrarían que este proceso fue más complejo, disruptivo y desigual. 
ciones» misionales, muchas de ellas ubicadas en las periferias del virreinato peruano. La más conocidas fueron las del Paraguay, Moxos y Juli, donde se enriquecerían con el tráfico y comercio de la yerba mate y otros productos, aprovechando su condición fronteriza y la escasa vigilancia de las autoridades coloniales.

Los franciscanos que fueron misioneros por excelencia incursionaron primeros en la selva desde el convento de los Descalzos en Lima y luego del de Ocopa construido en 1725. Aunque por sus métodos ortodoxos, no sólo tachonaron de mártires su historia, sino que en 1742 estalló la gran revuelta de Juan Santos Atahualpa que prácticamente paralizó la presencia europea en la región hasta fines del siglo XVIII.

Del mismo modo la evangelización protestante no ha estado exenta de estos estudios. El caso más representativo según nuestra opinión es el de los pentecostales aymaras de la frontera chileno-boliviana en el siglo XX (Van Kessel, 2008).

El trabajo de La Serna (2012) nos parece también interesante, pues desde la historiografía nos sumerge en el funcionamiento interno de la evangelización adventista de un grupo étnico del piedemonte amazónico: los asháninkas. El paquete era casi completo: adventismo, modernidad, individualidad, progreso y eficacia técnica; que en palabras del autor se convirtió en una «fuerza permanente e institucional al servicio del Estado» (p. 64).

Tal es así que, en una región como Puno del primer tercio del siglo XX, los adventistas despertaron el entusiasmo de intelectuales indigenistas. No olvidemos que personajes cómo José Antonio Encinas (1888-1958) le dedicaría algunas páginas de elogio, pues el predicador Fernando Stahl sellaría una alianza con el curaca Manuel Zúñiga Camacho, destacado líder aymara (Encinas 1968, Núñez, 2008).

Luego, cuando el predicador se desplaza con su misión hacia la selva central, un área con otros recursos y con un entorno regional más dinámico, es que esta iglesia se enraíza entre los asháninkas y los colonos. Desde San Luis de Shuaro se adentraron hacia Metraro (lugar importante para el mesianismo arawac), Chanchamayo y Perené. Quizá aquí, el mesianismo amazónico (la tierra sin mal) se haya soldado con las ideas y prácticas adventistas.

En ese sentido, las misiones cualesquiera sean su denominación $\mathrm{u}$ origen estuvieron en consonancia con la expansión económica, el de constituirse en «frentes externos» y en modelos de "nacionalización de las regiones».

\subsection{Los dominicos}

La Orden Dominica junto a la franciscana y los jerónimos fueron los primeros en llegar a tierras americanas, la Orden de los Predicadores se asentó desde 1510 en nuestro continente, con la llegada de cuatro frailes a la isla de Santo Domingo. Su importancia se debe a que desde el convento de San Esteban y de la Universidad de Salamanca emergieron voces y plumas como Vitoria, Soto y el mismo Las Casas.

Sin embargo, en la invasión de Pizarro y la toma de la ciudad de Cajamarca, estuvo presente fray Vicente de Valverde quien era parte de los seis curas dominicos que llegaron al Perú. Valverde sería el primer obispo del Cusco (1538-1541) en la primera etapa de la colonización europea y la presencia de esta orden en el Cusco data desde 1534 y su convento fue "el primero de esa Orden que se estableció en el Perú» (Vidal, 1958: 86).

Ya para esta época muchos religiosos se plantearon las estrategias de evangelización que oscilaban entre la "tabula rasa» a los modelos de sustitución. Esta última había sido practicada en Europa y se concentraban en la sustitución de lugares sagrados y de ciertos complejos culturales análogos o parecidos a los de la fe cristiana.

Erradicar las antiguas creencias religiosas sobre todo de sociedades complejas como la andina y la mesoamericana, siempre fue fundamental para el imperio colonial, pues siempre les rondaba la preocupación de que sus creencias, dioses y rituales prehispánicas estuvieran agazapadas «siempre prestas a retoñar en nuevos injertos» según la expresión de Solange Alberro (1981:11).

Volviendo a Valverde como fraile de la conquista, el cronista franciscano Meléndez narra su actuación a su paso por el valle de Jauja:

[...] ni fue sola en este género esta hazaña del padre Fr. Vicente, que cuantas huacas hallaba por los caminos las pisaba y echaba por el suelo (llaman huacas los indios no solamente a los ídolos sino a todos los lugares adonde los adoran...) levantando su celo en todas partes el estandarte santísimo de la cruz» (en Pérez, 1986). 
Con la reorganización del virreinato hecha por Toledo, los dominicos son desalojados del poder en beneficio de los jesuitas. Aunque las regiones de Charcas y el Cusco serán aún, sus valiosos reductos, aunque se encontraban ya muy debilitadas sus voces defensoras de indios. ${ }^{5}$

Sin embargo, tuvieron una presencia importante en el periodo pre-toledano. En 1534 se instalaron en el Collao, cuyo centro de gravitación fue la reducción de Juli.

A partir del primer Concilio Limense de 1552, la Orden de los Predicadores de la Provincia de San Juan Bautista tendrán las armas para avanzar en la evangelización indígena. En 1541 existían conventos en Quito, Huánuco, Trujillo, Huamanga, Guaylas y el valle de Jauja.

En 1571 fundan la universidad de San Marcos como Real y Pontificia, cuyo primer rector sería Tomás de San Martín y junto a él, como colaborador cercano, el teólogo Fray Francisco de la Cruz (quien había sido evangelizador de indios en Chucuito y Charcas), condenado a la hoguera en 1578 en la Plaza Mayor se Lima, por sus ideas alumbradas y que según Bataillon, sería una muestra de la «reacción antilascasiana» emprendida por Toledo (Bataillon 1976). En 1560 Domingo de Santo Tomás publica la primera Gramática quechua, para luego ser ungido como obispo de Charcas en 1562.

Ya en el clima barroco del siglo XVII, fructificarán santos dominicos como fray Martín de Porres, Rosa de Lima y el beato Juan Macías.

\section{La región del Cusco oriental}

El Cusco para fines del siglo XVIII había incorporado en cierta medida los valles orientales de las provincias de Lares y Paucartambo, las cuales producían importantes cantidades de coca y azúcar, cultivos importantes para el mercado interno de la región. Para 1820 se experimenta un retroceso de la frontera agrícola, quizás por el establecimiento de nuevos circuitos regionales y

5 El templo de Santo Domingo fue erigido sobre las bases del templo de Coricancha, y en una de sus celdas de la parte alta del monumento, Diego de Ojeda escribió "La Cristiada», hechos que atestiguan su importancia institucional durante la etapa temprana de la colonia. también por la importancia de la coca boliviana que provenía desde las yungas de La Paz. (Glave, 1980)

En 1823 el primer prefecto republicano del Cusco, el general Agustín Gamarra, ordenó una exploración a la selva al mando de un tal Zevallos. En 1836, se explora el valle de Marcapata por una denominada "Sociedad Expedicionaria» dirigida por notables como José María Pacheco y apoyada por el mencionado subprefecto (Pilar García, 1998: 411).

En 1840 en el valle de Santa Ana, el hacendado José Uriona junto a los frailes Ramón Bousquet y Pablo Forjas se coludieron para la explotación de cascarilla que se había convertido en ese momento, en uno de los rubros más representativos de exportación.

Ya con el gobierno de Castilla es por 1845, que recién se incorpora la Amazonia al imaginario republicano. Estas ideas se reforzaron con viejas miradas coloniales y reafirmadas por los hacendados criollos de la República, como fueron «la feracidad del territorio» o «la barbarie de los indios amazónicos».

En ese sentido es importante mencionar que un franciscano como el italiano Julián Bovo de Revello realizaría un viaje de exploración entre 1847- 1850 y en 1851-1852. Partieron de Paucartambo, donde sus habitantes conocidos como «naturales de la Amazonia», eran temidos por su ferocidad.

Las zonas de «avanzada» que habían consolidado áreas agrícolas productoras de coca, café, cacao y alcohol de caña, eran Echarati y Santa Ana, donde muchos de los peones (como también sus atacantes) eran "chunchos»: antis y chontaquiros.

En 1860 el presidente Balta dispuso la creación de la "Junta de Mainique» para colonizar las partes bajas del Urubamba. En 1873 un grupo de hacendados de Quillabamba, representados por Mariano Vargas y Martín Pío Concha, solicitaron a la Prefectura del Cusco, permisos para iniciar exploraciones y eventualmente "colonizar» las tierras bajas (Abarca, 2011:126).

En 1874 el presidente Manuel Prado aprobaría la autorización de la «Empresa de Conversión y Reducción de las Tribus de Campas y Piros» ni más ni menos, por el cual recibiría 4,000 soles para iniciar las expediciones.

Lo destacable de esta asociación no fue su pronta disolución, sino sus intereses comerciales explícitos como por ejemplo el «cobrar por 50 ańos el peaje de los productos que exporten e importen", "propiedad 
exclusiva de las tierras baldías" y "concesión por 20 años de la alcabala de la coca en la provincia de La Convención» (Abarca 2011:127).

\section{«Madre de Dios»}

La región de Madre de Dios anexa a la región del Cusco en este siglo de incorporación amazónica, también fue objeto de expediciones que ingresaron por Puno a través de Sandia y Carabaya, de las cuales extraían la cascarilla. En conjunción con los misioneros se establecieron las escuelas de Shintuya, Diamante, Toyakane, etc. El siguiente paso sería el de abrir vías de comunicación.

Los valles orientales se constituyeron así, en una importante zona que alimentaba a la región del Cusco de productos con alto valor comercial. Según Morner (1978: 81) la zona arrojaba unas 6,000 arrobas de coca para 1803 . La propia revista MDP, da la noticia de la introducción de semillas de té y canela hechas por Benjamín de la Torre en la hacienda Huyro en 1907, para 1908 ya se habían producido 172,000 arrobas de coca.

Como dato curioso en MDP XIII (62) enerofebrero de 1931, un articulista, el ingeniero y viajero Cristian Bues menciona que hacia 1899, en la hacienda de Santa Ana en Quillabamba, se había elaborado cocaína que, para la época, era considerada un producto más digno de la curiosidad.

Como fronteriza y abierta a la "colonización» en esta zona la hacienda era la institución común en el paisaje. Brisseau (1981) ofrece una lista de haciendas que existían antes de la reforma agraria de 1969. En ella destacan instituciones cuya presencia venía desde inicios de la república, como la orden mercedaria y la Beneficencia Pública. Los primeros poseían la conocida hacienda Huyro con casi 4 mil hectáreas y la Beneficencia, Sicre y Huayabamba en La Convención con 98 mil hectáreas.

\section{Abordando de la diferencia}

La narrativa misionera, que expondremos con cierto detalle más adelante, está construida basada en el binomio barbarie/civilización. La barbarie está asociada a un conjunto de atributos antitéticos a los del ámbito de la civilización. Opera por contraste (como toda clasificación binaria) y se define en oposición al otro en espacios simbólicos, sociales y territoriales. No olvidemos que para Colón, el nuevo sujeto americano fue descrito en oposición a los europeos de la época: estaban desnudos, eran pacíficos y no conocían el comercio (Pastor 1983).

Todas las descripciones sobre el poblador amazónico tendrán ese tándem discursivo. Thompson un adventista a órdenes de Stahl escribirá en 1928 que estos deben ser «civilizados, bien vestidos, limpios, cultivando el suelo» (La Serna, 2012:127).

El franciscano Amich, cronista de los viajes y explorador de la orden por la selva central, lo dice sin ambages que "su comida es muy asquerosa» (1988: 303), lo cual recuerda con el ánimo de ser plurales, mostrar que ese discurso no fue privativo de los religiosos, la opinión de un "etnólogo» citado por Karsten en su artículo sobre los shipibos-conibos del Ucayali, en una época algo ya tardía de que: «Los shipibos están en una etapa animal y son inferiores a los negros» (1955: 173).

Los rasgos de su estructura social que no se amoldaban a las reducciones y las necesidades de los "capitanes» de la industria, eran vistos de esta manera: "Como el género de vida de estos indios, son muy pocas las necesidades que se dejen sentir apenas necesitan trabajo alguno para satisfacérseles. Y es así como pasan la mayor parte del tiempo en la más completa ociosidad» (1988: 303).

Como ejemplo tenemos el juicio del dominico Fernández sobre el sistema matrimonial matsiguenga y que publicará en sus memorias: «La poligamia, aunque es bastante general, en muchas agrupaciones solo se le permite al grupo. Respetan el parentesco en varios grados respecto a matrimonios, y se aman los parientes y se favorecen mutuamente».

Pero: «En donde su moral flaquea y delinque con horrores, es en la vida íntima de los hogares; allí, a la tenue luz de un tizón, o bien alumbradas por varias fogatas de otras tantas familias, pierden la vergüenza, se convierten las chozas en templos a Venus».

Lo que faltaba, un misionero voyeur. Pero hay más, Amich vuelve a decir: "Cuéntase que son los cashibos tan apasionados por la carne humana, que no se perdonan ni aún entre ellos mismos» (1988: 305).

Cuando abordan la «religión matsingenga» no tienen herramientas conceptuales para entender un 
sistema sin dioses inconmensurables y reacios a ser representados, por lo que describen a estos pueblos como «estoicos» $\mathrm{y}$ «ateos». ${ }^{6}$

\section{La revista Misiones Dominicanas del Perú7}

«Una revista más? - Sí, señor; una revista más. No se asuste; porque nadie está obligado a tomarla, ni a leerla. Si U. no tiene interés en nuestra obra, déjenos vivir y que salga esta Revista como salen tantas otras con menos razón para que existan».

Así apareció en Lima esta publicación en 1919 y que fue publicada hasta $1968^{8}$. Fue diseñada trimestralmente, aunque luego se convertiría en bimestral. Tenía como objetivo informar al público y al gobierno del avance de la actividad misional en la provincia dominica de la selva. En el país, la suscripción anual tenía un valor de 1 sol y el número suelto de 30 centavos. En España, costaba 5 pesetas la suscripción anual.

Cuando se lee la revista en un periodo más o menos largo, nos vamos dando cuenta de que poseía algunas secciones publicadas con cierta regularidad. Están, por ejemplo, las noticias propias de las misiones redactas con un tono de heroicidad y sacrificio, enfrentados casi siempre a la hostilidad del paisaje y de los salvajes. Luego está la sección de Crónicas, con reseńas biográficas y la correspondencia de los misioneros españoles.

Luego más adelante, aparecen descripciones geográficas y etnográficas que creemos, constituyen el material más valioso para nuestra investigación. Así mismo, cuando se habla de la labor misional también ofrecen noticias sobre sus actividades en Cusco, Arequipa, Lima y Huacho donde poseían colegios y

MDP (III) 11, setiembre-octubre, 1921.

Sobre la importancia de la revista en el ámbito de la misionología pueden verse Monika Ludescher (200/2001) e Isabel Serra Pfennig (2017).

8 Nos hemos detenido en 1940 porque consideramos que hasta ese año era visible una narrativa consistente y semejante. Además, porque en los años 50 y 60, hubo cambios en la percepción de las comunidades indígenas, los textos al volverse más laicos y desarrollistas vuelve casi invisible la antigua textualidad. Los años del crecimiento económico y las políticas de Estado van disolviendo el concepto tradicional de las misiones. una gran actividad religiosa y de propaganda entre la población urbana. ${ }^{9}$

Casi desde su fundación esta publicación incluía avisajes comerciales que eran también uno de los medios de su financiamiento. Para 1924 por ejemplo, se publicitaban las casas comerciales Gallese, Roggero, Copello, Fort y Ferrand.

En los años 30, aparece la publicidad de compañías más grandes como la cervecería Cristal, la empresa de aviación Panagra, la casa Yachikawa y el Banco Italiano. Empresas más globales y corporativas, que garantizaron en cierto modo la continuidad de la publicación de la revista.

\section{Piezas narrativas}

1. En la revista MDP enero-marzo de 1919, se menciona al misionero como «un enviado de Dios» y nos relata la travesía de las tres primeras dominicas en la selva: Sor Angélica, Sor Aurora y Sor Ascensión del Sagrado Corazón.

Ellas parten del Callao hasta el puerto de Mollendo de ahí, a Arequipa, pasan por Juliaca —en todos aquellos lugares son recibidos y confortados por autoridades eclesiales y civiles - luego ya en Tirapata emprenden camino hacia la selva, donde los esperaba el padre Pío quien había llegado del Cusco con la "chunchita Carmen» "salvaje hasta simpática y tratable».

Pasan por Asillo, Progreso y Puerto Arturo donde avistan "pobres gentes, con que poco se contentan y que abandono religioso se nota en estos pueblos».

Llegan a Crucero en plena cordillera, Huancarará, Limbari, Quitún, Número Cinco, Caparpa, Candamo y Astillero, ya en la Selva. Un viaje combinado entre lomo de mulas y caballos, algún vehículo motorizado y navegación fluvial. Escrita por las misioneras y dirigidas a la autoridad religiosa este documento grafica las dificultades de comunicación de la época, pero también, como la naturaleza esencial de las misiones: dificultad y sacrificio.

2. En MDP marzo-junio 1919, Pío Aza le escribe al subprefecto de Manu donde relata que unos vecinos

9 Para efectos del trabajo, la revista será citada sólo por el trimestre y el año de publicación, omitiendo los números de volumen y orden correlativo. Por ejemplo, el primer número: Año 1, número 1, eneromarzo de 1919, será citado como MDP I (1), enero-marzo, 1919. 
de Madre de Dios se quejan de «las dificultades y obstáculos que los misioneros de este departamento ofrecen a las exploraciones que ellos piensan hacer...» Según la carta, pedían a la autoridad política que les «otorgue amparo y garantías» para recorrer esas zonas inexploradas en la zona de Colorado, para caucheros y lavadores de oro.

Lo que Pío Aza explica es que los misioneros se oponían a las «correrías» de los «exploradores» y el abuso y secuestro de los nativos. No olvidemos que Carlos Fry, mencionada en su diario de 1886, la dificultad de los caucheros de obtener mano de obra, por la influencia misional.

Luego en una nota necrológica anuncian que «la salvajita Dolores» quien fue acogida en la misión del Manu, había fallecido. La nota, la hace el padre Vicente Cenitagoya.

3. MDP enero-marzo y de abril-junio de 1920, están dedicados a la descripción de los «ríos principales del departamento de Madre de Dios» y la "flora», como a recorrer las «chozas de los salvajes». En estos números se empiezan a utilizar fotografías.

Pareciese lo que Pratt en Ojos Imperiales (2010) escribirá de las descripciones colonialistas del África del Sur «un apartheid textual que separa el paisaje de la gente, los relatos de los habitantes de las descripciones de sus hábitats» (2010, p.125).

4. En MDP, julio-setiembre de 1920, aparece un poema Oda a América:

¡Salve, genio sublime del hispano,

Que hiciste esclava de tu honor la gloria

Trazando sobre el suelo americano

¡La epopeya más grande de la historia!

El espíritu nacionalista español incubado en un pensamiento castrense y conservador: monárquico y católico, que por ese momento guiaba la praxis misionera.

5. MDP, enero-marzo de 1921, da la noticia que, en marzo de 1921, se produce un ataque a la Casa Misión de San Jacinto. En dicha casa según la información, estaban internados 25 niños y 50 niñas. En este mismo número un misionero relata que en 1913 participó de una sesión de exorcismo en plena selva.
6. MDP, abril-agosto de 1921, existe un extenso editorial llamado "La crisis de la Montaña». Con un tono pesimista y de alarma, recuerda con nostalgia mejores épocas de "prosperidad y abundancia». Se supone que la crisis regional hace que también como en un juego de bandas, afecten las misiones. El padre José Álvarez describe una travesía por el río Blanco y como en un momento se acerca a una choza y descubre el utillaje: «La profunda pena que se grabó en mi alma al contemplar aquellos objetos, símbolos de superstición y de la desdicha eterna, aún me aflige...».

El misionero siente angustia por descubrir un entierro en esa choza: enseres y objetos propios de una cultura extrańa e incompresible para el dominico. Como si se contemplase un mundo lejano y raro y más aún, pagano. ${ }^{10}$

\section{"Las mayores dificultades: la geográfica y la étnica»}

Aunque en el siglo XIX, la prédica religiosa fue pacífi$\mathrm{ca}$, en el caso de los dominicos, su verbo civilizatorio fue igual de contundente. En el siglo XX estará ya diseminada la idea de «integración», y no será hasta el primer gobierno de Belaunde (1963-1968) que se planifique sistemáticamente la articulación vial de la selva con el resto del país y se promuevan colonizaciones para expandir la agricultura y el asentamiento de pueblos mestizos, con una óptica desarrollista.

En una carta del padre de Sales Soto de los Sagrados Corazones dirigida al dominico Alberto Delgado fechada en 1898 le dirá: «V.R. sabe que las regiones salvajes son mayores en extensión que la parte civilizada del Perú. Numerosas tribus enteramente salvajes y otras bárbaras habitan tan extensas comarcas, permaneciendo esas gentes en la idolatría y en la degradación por falta de la luz de las verdades eternas..." y luego alienta al dominico pues estos «tiene los más profundos títulos para ser llamada la primera a tan gloriosa empresa.» «Sus tradiciones le dan derecho y la impulsan, diría, a recuperar por este medio el puesto que tuvo desde la Conquista» (Castańeda 1983).

10 Antes de que este artículo ingrese a imprenta, nuevamente se ha desatado el escándalo tanto en la prensa mundial como en los medios académicos, sobre el descubrimiento de nuevas fosas de nińos originarios en internados católicos del Canadá. Entre 1863 y 1999, se separaron de sus hogares a más de 150,000 niños, de los cuales murieron 6,000 por maltratos y enfermedades. 
El dominico presto, responde por la misma fecha "cuando estimo propio de mi vocación dominicana, el contribuir decididamente de las almas más necesitadas del auxilio espiritual, como son la de los salvajes...» (Castañeda, 1983).

Creada el 5 de febrero de 1902, la Provincia Apostólica del Urubamba y Madre de Dios, tuvo como primer responsable al padre Ramón Zubieta, quien luego fuese ungido Obispo Titular de las misiones. Zubieta llegaría junto a los misioneros José María Palacio y Francisco Cuesta. Salen del puerto de Cádiz el 15 de enero de 1902 y arriban al Callao el 21 del mismo mes.

Su territorio misional abarcó originalmente los territorios de Quillabamba, Maldonado y Tahuamanu. Luego lo sucedería Sabas Sarasola quien funda la Granja Escuela de Quillabamba, que al igual que la Granja Salcedo de los adventistas en Puno, serán un modelo disciplinante y de aculturación religiosa.

Los accidentes y los riesgos que corrieron los misioneros son relatados con detalle para exaltar el heroísmo. Por ejemplo, el P. Enrique Álvarez muere ahogado, la muerte de Álvarez es el inicio de una serie de bajas de la orden. Manuel Marina muere a manos de los Huarayos en 1926. José Arnaldo cae en 1937 flechado por los Ińaparis, José Torres y Bonifacio Fernández se ahogan en el río Madre de Dios en 1906 y 1911, respectivamente.

Jacinto García quien había servido en Pantiacolla y el Manu, moriría no en la selva peruana, sino en 1936 por los «rojos» en plena guerra civil española. Obviamente el término de «rojo» estaba muy al tono con el diccionario franquista, que los dominicos españoles en el Perú (y de la iglesia peruana en general) compartían y simpatizaban.

Eso explica por qué Sarasola en MDP IX (43) de noviembre-diciembre de 1927 se lamente de la situación de la iglesia católica en México: «las iglesias han sido expoliadas y convertidas en oficinas de la revolución» (43:209).

En esa misma línea un editorial de MDP V (25) de noviembre-diciembre de 1925, despotrica contra el feminismo, idea precursora junto al modernismo literario y la estética de vanguardia de la Lima de entonces: «Sólo un extravío producido por la pasión y la ignorancia pueden intentar establecer entre los seres una igualdad que la naturaleza no ha establecido» «Parece que se intentara que la mujer fuera ocupando el campo que el hombre por su afeminamiento va abandonando".

Finalmente, este recuento expresa lo que José María Grain, vicario apostólico de Puerto Maldonado, diría resumidamente de esta difícil labor para esos españoles que habían estado antes en Filipinas, que sus mayores dificultades eran "geográficas y étnicas».

Así, esas dos cuestiones se ensamblaban con las necesidades del Estado peruano que necesitaba (y auspiciaba) las exploraciones geográficas, la inmigración europea y el subsidio a las élites regionales de Chachapoyas, Huánuco, Tarma y Cusco.

El otro "problema» era tan antiguo como la colonización. Los «salvajes», «infieles» «ovejas escondidas en la selva" y todo el abanico semántico para su adjetivación y clasificación, era para declararlos no sólo infieles sino sobre todo inferiores.

Como diría un misionero: "Al regreso de mi expedición saqué un niño salvaje, como de seis años de edad, perteneciente a la raza campa, lo tengo en mi compañía, y podrá ser un elemento útil».

Y otro, misionero en Chumbiría, se refiere de su ayudante evangelizada: "Una mujer machinguenga llamada Honorata: moral, hacendosa, obediente». (Fernández 1952: 100).

Esta retórica de la domesticación, evocaba y reproducía el modelo de la reducción colonial. Evitando la dispersión, se concentraba a los colonizados, colocándolos como mano de obra. Lo que Albert Memmi, llamaría la «marca del plural» (Bonfil 1972:114). Toda singularidad es refractaria para los proyectos totalitarios, la homogenización opera como una «aplanadora mental» tanto para los colonizados como para los colonizadores.

\section{«Naturaleza feraz e inexpugnable»}

«Mucho, casi infinito es lo que hay admirar allí. Su vegetación, más que lujuriosa (como diría algún pedantuelo modernista) se podría llamar iracunda. Las plantas brotan con furia por doquier, y se disputan el terreno palmo a palmo, y se cruzan, se retuercen y se entrelazan entre sí, y luchan cuerpo a cuerpo con esfuerzo titánico hasta matarse,» reza un editorial.

Esta sección es importante pues se conecta con las siguientes. El salvaje se compagina con la naturaleza no domesticada y en ese trayecto, la empresa misionera adquiere inusitado valor justamente porque 
enfrentarse al hombre/naturaleza insumiso e incomprensible, requiere de valores cristianos insuperables: pobreza, sacrificio, conducta ejemplar, estoicidad y entre líneas, del espíritu indomable español, sobre todo en aquellas regiones montañosas donde la vida también requiere de entereza: Asturias o Navarra.

En la revista, las descripciones geográficas ocupan un lugar importante. Se escribe sobre los ríos, paisajes, pueblos y de la dificultad de llegar a ellas y por ellas. Por ejemplo, en MDP $50^{11}$ se inaugura una crónica sobre «Impresiones de las selvas» intercaladas con fotografías.

Por la misma época se discutía la importancia de la penetración hacia la selva auspiciada por el Estado, ya más fortalecido con la prosperidad de la posguerra. En este número se preguntan si el voceado acceso de Quillabamba hacia el norte conviene una carretera o un Ferrocarril. Conexión vial, evangelización y desarrollo mercantil de la ceja de selva como un pack moderno.

En MDP $59^{12}$ el padre Sarasola escribe una pequeña serie de artículos con el título de «De Maldonado a Acre», donde se adentra hacia Bolivia y el tono narrativo es el mismo: causar asombro y perplejidad sobre esas tierras ignotas y fortalecer en el lector, la importancia de la acción misionera.

Por ejemplo, ni los "civilizados» se salvan: "Aunque los brasileños son devotos, no saben ni persignarse» ${ }^{13}$. Álvarez dirá: "Como la gente que habita ese río [Tahuamanu] se ha trasladado en gran parte al río Ucayali, sólo pude hacer diez bautismos, entre salvajes y civilizados» (Soria 1998:65).

\section{La frontera civilizatoria}

La valoración cultural es un tema recurrente de suma importancia. No solo determinan las tácticas de evangelización, sino que también ofrece la oportunidad de incursionar en la etnografía. En MDP $18^{14}$ el dominico Vicente Cenitagoya se dedicará en adelante de ilustrarnos sobre las características sociales y culturales de los grupos étnicos del Urubamba y de Madre de Dios.

11 MDP XI (50), enero-febrero, 1929.

12 MDP XII (59) julio-agosto, 1930.

13 MDP I (4) julio-setiembre, 1919.

14 MDP V (18) setiembre, 1923.
Dos géneros de hombres salvajes tenemos allí que estudiar: el civilizado salvaje y el salvaje sin civilizar. El primero no es más que la bestia humana, azuzada por el espíritu del mal, y entregada sin freno ni traba al frenesí de sus depravados instintos. El segundo no es más que la pura bestia humana, sin otras aspiraciones ni exigencias que las que despiertan en ella las necesidades primordiales de la naturaleza. Este segundo tipo es incomparablemente más inocente que el primero.

Titulada la serie «Una visita a los machiguengas» describe no sólo algunas de sus costumbres (con énfasis monográfico, pues siempre empiezan por las actividades de subsistencia, luego su dieta, la organización social y sus creencias) sino también como la sombra civilizadora va cubriendo la vida de estas sociedades.

Uno de los indicadores de esa "sombra» es el bautismo y el uso de los nuevos patronímicos como signos de «cristianización». Por ejemplo, en este número se inserta una carta del padre Wenceslao Fernández escrita en San José de Koribeni en julio de $1924 .{ }^{15}$ En ella, da cuenta del matrimonio de Domingo con Justina no bautizada, que luego es cambiada de nombre por Francisca.

En MDP $29^{16}$ aparece "Los salvajes de Madre de Dios. Rasgos de su vida íntima» $\mathrm{y}$ "Estudios sobre etnografía y farmacopea salvaje» de Wenceslao Fernández. El del $31^{17}$ sorprende con «Del salvaje como objeto de estudio» que empieza así:

La generalidad son leprosos (carachosos como dirían los loretanos); llenos de asquerosas manchas y de otras diversas afecciones cutáneas; francas manifestaciones de la impureza de su sangre, como, por ejemplo, las variadas maneras de escrofulosis, que persisten en todas las edades, y duran toda la vida, y son hereditarias de generación en generación. (Fernández 1952: 481)

Antes se inaugura el drama íntimo «Entre salvajes Huarayos» con ocho escenas. En el mismo número 31, en la sección "De las misiones» hay una curiosa observación, es el sentido de que los «salvajes» (nó-

15 En el Urubamba se establecieron las misiones de Chirumbía, Koribeni y Sepahua. En Madre de Dios, Cosñipata o Asunción de Santa Rosa, Santa Rosa del lago de Valencia y Panticolla, San Jacinto, El Pilar, San Miguel de los Mashcos, Quincemil e Iberia.

16 MDP VII (29) julio-agosto, 1925.

17 MDP VII, (31) noviembre-diciembre, 1925. 
mades e itinerantes) poseen aversión por los animales domésticos. Los «salvajes» amazónicos han rechazado muchas veces la agricultura permanente y la crianza de animales, para evitar las aldeas permanentes y garantizar su permanente fisión social, características comunes en las tierras bajas sudamericanas.

En el MDP $33^{18}$ se relata el bautismo y la primera comunión de la salvajita Huaraya, que nombran Lourdes. Pío Aza publica «La aglutinación de las lenguas salvajes» en MDP IX (41) de 1927. En este periodo de la revista ya pasado el asombro, le sigue un intento de sistematización de los grupos indígenas, con el utillaje conceptual de los misioneros: una sociología ingenua, una etnografía descriptiva, y un relamido determinismo geográfico.

"Cosas de salvajes», "Escenas de la vida salvaje y «Los Salvajes Machiguengas. Contribución para el estudio de las razas amazónicas» de Cenitagoya y «La tribu Huaraya», "Gramática de las lenguas salvajes» de Pío Aza o «Un mes con los salvajes en la selva» de Fr. Gerardo Fernández son una muestra del nuevo interés por la «reflexión científica». ${ }^{19}$

\section{Aventuras e ideales misioneros}

En junio de 1927 los dominicos estrenan una «película misional» en el teatro Forero de Lima, según anotaría el diario El Comercio. Dicha película en 4 actos sirvió de propaganda y sensibilización ante un público ubicado en las antípodas de la realidad amazónica. También tenía como objetivo el de recabar fondos entre la mayoría católica de la Lima de entonces.

El MDP (3) 12, de diciembre de 1921, está dedicado a la muerte de Ramón Zubiate y Les, ocurrida el 19 de noviembre de ese año en Huacho, ciudad portuaria al norte de Lima. Dicho número tiene como telón, el magnífico título de El Hombre-El explorador-El misionero-El fundador.

Efectivamente, muchas de esas cosas fue Zubiate. Fue el arquitecto de la obra dominica en la región. Sus logros religiosos fueron aquilatados por la sociedad limeña, pero también por las élites regionales de Cusco y Madre de Dios. Por ejemplo, en una carta dirigida el 04 de diciembre de 1911 a María

18 MDP VIII (33), mayo-abril 1926

19 MDP XII (61), noviembre-diciembre; 1930, MDP XIII (62), enerofebrero, 1931; MDP XIII (67), noviembre-diciembre, 1931.
Cordero en ese momento benefactora del Comité de Propaganda Fide (que también se oficiaba como nexo entre ciertas capas limeñas y el gobierno) que en su jurisdicción de «salvajes,» el balance era por el momento de 353 bautizados, 241 confirmados y 17 matrimonios.

Otro personaje importante fue José Álvarez, llamado Apacktone por los machcos o Papachí por los huarayos, términos que significan padre o protector. Exploró importantes ríos de Madre de Dios, como el Malinowski, Tahuamanu, Heath, Madre de Dios y el lago Valencia. Por lo cual, sería reconocido por el presidente Fernando Belaunde (1963-1968), pues su labor en gran medida gratificaba su vocación integradora sobre la selva.

Obviamente Álvarez representaba la excelsitud del paternalismo religioso, quizás pudo inspirar en ese entonces, la formación de misioneros españoles en el Monasterio de Corias en Asturias. En una España centralizada y con férreo control, los polos regionales periféricos (Navarra/Asturias/Extremadura/ Amazonia) se acercaban y tocaban.

Otro aspecto importante es el caso del desmembramiento familiar como secuela del colonialismo. Es decir que la familia fuese destruida ante políticas de evangelización o reordenamiento territorial. Sucedió en América colonial. Ya la historiografía americana ha relatado el caso de los suicidios colectivos en las etapas tempranas de la colonización en los Andes, o las tragedias familiares ante el drenaje de los varones hacia la mita minera en Huancavelica o Potosí, relatada con animosidad por los jesuitas del siglo XVII (Vargas 1951).

También sucedió en Canadá y Australia, tal como lo ha relatado Pratt (2010). Muchas políticas coloniales, desgajaron familias enteras para que los niños sean recluidos en albergues especiales separados de sus padres y luego "aculturados» para que una vez incorporados a la «sociedad nacional» sean integrados a los estratos más bajos de la sociedad, como sirvientes o lacayos.

En MDP XI (52), mayo-junio 1929, se relata el caso de una madre que no desea separarse de su hija quien marcha a un internado en Quillabamba: "Compadre — lo soy de verdad — he oído que vas a llaver a mi hija al colegio. No la lleves, porque si no voy a tener mucha pena. Dado caso de que la lleves, yo, también me voy a ir con ella». 
-'Vete, si quieres; pero ten en cuenta que en Quillabamba no hay yuca ni plátano, y si deseas comer, tienes que comprar y tu careces de plata. ¿Además, dónde vas a vivir?’

-'En las madres'.

-AAllí no admiten mujeres casadas'.

-'Entonces viviré en la casa de los Padres'.

-'Menos aún, porque en la casa de los Padres no pueden vivir mujeres'.

Muchas mujeres que hacían trabajos de servidumbre en las ciudades andinas y de la costa, tenían parecidas historias. Desmembramiento familiar, cambios en sus patronímicos y sumisión al mundo hegemónico. Sarasola cuando celebra un matrimonio de matsiguengas bautizados ya, se refiere a la consorte criada por ellos como «Francisca la del rostro triste» o el bautismo y la primera comunión de la salvajita huaraya, ya llamada «Lourdes». ${ }^{20}$

\section{La fotografía y la visualidad dominica}

La revista casi desde sus inicios tuvo la ventaja de incorporar en sus páginas dibujos y fotografías. Esta temprana apuesta por la visualidad tuvo dos razones básicas, la primera es que la convirtió en una prueba fehaciente y "objetiva» de su actividad misionera, casi con fidelidad testifical. La segunda, fue una vía de comunicación visual con el público lector, un segmento que, además, podía influenciar para que eventualmente pudieran obtener ventajas institucionales y materiales para la continuación de su labor en general.

Las fotos que formaron parte de la revista tuvieron una connotación que otorgaba identidad y sentido tanto para los misioneros como para los lectores, más aún, en un medio en donde la prensa en general todavía no usaba la fotografía como parte del texto periodístico.

Pero también había una visualidad etnográfica, donde se exponía al otro distinto. Textos visuales con significantes de muchas dimensiones. En el aparente naturalismo y deseo de fuerza expresiva mediante la imagen, se traslucían signos e ideas.

Así tenemos, fotografías de familias y personajes, retratos de misioneros en sus chozas y con el bosque

20 MDP VIII (33) marzo-abril, 1926. como fondo o decoración: una otredad recurrente pero también, de poder frente al ícono inerme y retratado (Pérez, 2016). La naturaleza y el hombre de la selva tropical fueron vistos y traducidos como caóticos, caóticos por su salvajismo, por su falta de orden y normalidad (policía en el viejo lenguaje colonial), por su exuberancia y descontrol que estaban a la espera de un encorsetamiento.

Es en ese escenario que el trabajo misionero aparece en contraposición, cómo ordenador; la irrupción visual de ese orden (capillas, sacerdotes, monjas, exploradores, niños domesticados) concede eficacia y tranquilidad al lector visual. Como en el sueño, donde el despertar abrupto revela una realidad tranquilizadora que bloquea el un real (el otro), un despertar que se convierte en el sueño permanente que encubre lo que no queremos explorar o saber y que está a punto de convertirse en una pesadilla.

\section{Conclusiones}

En este artículo hemos intentado demostrar que la revista Misiones Dominicanas del Perú, en un periodo escogido que va desde su fundación en 1919 hasta 1940, representa la voz, la narrativa y las imágenes de una etapa de evangelización tardía en la Amazonia sureste del Perú.

A través de sus páginas, hemos intentado clasificar esos discursos e imágenes en tres rubros generales: la naturaleza, la cultura y la sociedad amazónicas y los valores misioneros. El primero, se refiere a la mirada ambivalente del paisaje y el territorio selváticos. De un lado, se exaltaba la exuberancia y la belleza indómita del paisaje tropical. Del otro, su dificultad y peligro para domeñarla. Ambas referencias estaban unidas por la certeza de lo prístino y lo pre-cultural.

La primera estuvo vinculada a imágenes «edénicas», en que la Amazonía fue vista y narrada como el paraíso perdido o la tierra de la abundancia. Aunque en este periodo de exploración y conquista hubo más bien un discurso ambivalente; mientras por un lado se exaltaba su naturaleza original (el primer encuentro «maravillado» lo ha llamado Marcone 1999), del otro, su geografía «salvaje», «bárbara».

No está más decir que en los primeros años de publicada la revista, el hombre selvático era parte de 
ese paisaje. Aspecto que por lo demás fue común en el razonamiento colonial (Said, 2003, Pratt, 2010).

Posteriormente la descripción del paisaje y el territorio cede también al interés clasificatorio. Aparecen artículos sobre la flora, la fauna o la descripción del curso y la utilidad de los ríos (como las series de 1922).

La sociedad y la cultura amazónica como sujetos y objetos de evangelización, fue aún más contradictoria. Las miradas estaban sujetas y sopesadas por las dificultades o facilidades para su aculturación.

En general eras descritas como «salvajes»; si bien era un término sin las connotaciones actuales (la antropología británica la utilizó hasta la segunda guerra mundial), ese estado de primitivismo estaba graduado.

Una situación muy distinta era lidiar con sociedades organizadas y en cierto modo sedentarizadas como las matsinguengas del piedemonte amazónico, y otra con grupos étnicos nómades, con economías recolectoras y hechas para la guerra, en el sentido que Clastres les otorga como los huarayo, machcos o los amahuacas de la selva baja. ${ }^{21}$

Conforme avanzaba la labor misionera y se constatan los avances del Estado por articular esa porción selvática al territorio peruano, crece el interés por categorizar (es decir clasificar y describir) a las sociedades originarias. Sobre todo, aquellas que eran más numerosas, más sedentarias y que fueron dóciles ante la arremetida dominica. La formación de haciendas de selva alta y la labor inhumana de caucheros, buscadores de oro y de fortuna (amparados muchas veces por las autoridades regionales y los propios misioneros), contribuyeron también a atraer los matsinguengas a las misiones.

21 En la revista se registran 16 grupos etnolingüísticos (huarayos, arajairis, toyeris, culinas, chamas, iñaparis, cocamas, amahuacas, campas, huitotos, santarosinos, marunkiaris, amarakairis, cabiñas y kugapakoris) y distribuidas en aproximadamente veinte cuencas y sub-cuencas hidrográficas de la entonces provincia apostólica de Urubamba y Madre de Dios. Esto plantea algunas cuestiones. Hoy, la etnología amazónica los ha clasificado con indicadores más precisos $y$, por lo tanto, ha fusionado o renombrado a muchos de estos grupos (la mayor de las veces con sus etnónimos). De otro lado, fueron los misioneros quienes bautizaron a su manera y capricho a estas sociedades a lo largo y ancho de América. Sólo como ejemplo, el famoso río Huancamayo o Hatunmayo, que atraviesa el actual departamento de Junín, fue renombrado como Mantaro - palabra asháninca- por los franciscanos de Ocopa en el siglo XVII. Sólo esto, nos llevaría a relacionar los problemas que conlleva la clasificación social, la cartografía y el colonialismo.
Santa Ana, Quillabamba o Koribeni en el Cusco y luego, el puerto de Madre de Dios serán la prueba de la evolución de este proceso. En esta etapa de curiosidad sistemática, es que se van desplazando conceptos cómo «miserables», «sarnositos», «ociosos», «infelices» o «lujuriosos»; para dar paso al parentesco, la lengua y la religión de los arawak («Del salvaje como objeto de estudio» 1925). Aquí ya aparecen en su narrativa, conceptos como "cosmología», "ateísmo» o los logros en sus técnicas de pesca, caza o agricultura.

Es la gran etapa del paternalismo, del «no discriminador con prejuicios» que apuntaba Robert Merton $^{22}$. Esto representaba no sólo el aggiornamento de las misiones, del reconocimiento del poder político a su labor, sino también los cambios de la iglesia en general y la pugna entre órdenes religiosas que también competían por las almas amazónicas: los agustinos de Loreto y los franciscanos de Ocopa.

Es aquí cuando surgen los dominicos más lúcidos como Pío Aza, Vicente Cenitagoya y Secundino García $^{23}$. Pioneros de la etnografía y la lingüística, que influirán no sólo en la futura sociología de la región, sino también en los propios dominicos ya iluminados a partir de la segunda mitad del siglo XX; por Juan XXIII, Paulo VI y una visión plural de América Latina y de su legado original.

Aza, publicará estudios sobre los machiguengas y los huarayos. Cenitagoya lo hará con "Los salvajes machiguengas. Contribución para el estudio de las razas amazónicas» en 1931. Wenceslao Fernández publicará finalmente en España «Cincuenta años en la selva amazónica», libro donde recopila todos sus artículos escritos en la revista MDP. ${ }^{24}$

La imagen que construyeron de sí mismos los dominicos también fue hecha para su consumo en las regiones adyacentes a su labor, como también para las autoridades nacionales de Lima y de los empresarios

22 La cita original es Merton, R. (1949). Discrimination and the American Creed. En R. Mac Lever (Ed.) Discrimination and National Welfare. New York: Harper \& Row. Lo cita Rodríguez, M.J. (2001) Etnicidad, Raza y Multiculturalismo: 77-78, en M.J. Rodríguez (Edit.). Temas en Sociología II. Madrid: Hurga y Hierro: 59-102.

23 Este dominico recopiló importantes mitos de la cuenca del Urubamba, y es citado por etnólogos contemporáneos como RenardCasevitz (1988) o Baer (1994).

24 En MDP V (17) julio de 1923, Aza publica «Orígenes de las tribus selváticas del Amazonas» en ella postula que «los primitivos pobladores de los Andes hayan procedido del Amazonas». En 1927 se adentra en la filología con "La aglutinación de las lenguas salvajes», en 1930 termina «La tribu Huaraya». 
piadosos que fueron útiles para su financiamiento. Este aspecto tratado en nuestro artículo se compagina con los otros dos. El éxito de las exploraciones geográficas y el control de las poblaciones evangelizadas, se explican por el heroísmo de las misiones, literatura tan antigua como los propios evangelios.

Así como algunos han planteado que la religión recibida en América sólo puede explicarse por las características peculiares del catolicismo español de la contrarreforma (tal como nos lo ha relatado Julio Caro Baroja) que derivó en su barroquismo y la vuelta del milagro; del mismo modo nos puede explicar el carácter de la evangelización tardía en el Perú.

El nacionalismo español (monárquico y católico) había destilado las ideas del heroísmo español. El de la reconquista, el de la construcción de un Imperio y de su noción de particularidad.

Este corpus ideológico no fue ajeno a los dominicos españoles que llegaron a la selva peruana. Como misioneros eran depositarios del estoicismo y la frugalidad. También del sacrificio y el heroísmo.

Eso explica las palabras exultantes ante la desaparición de Fr. Manuel García y García «muerto por los salvajes Huarayos el 3 de marzo de 1926».

Explica también su abierto apoyo a los nacionales en el curso de la guerra civil española (1936-1939) y luego, su adhesión al régimen franquista.

En resumen, postulamos que la presencia dominica en la selva sur, como la franciscana en la central, sirvió para ordenar el territorio, para que luego el Estado permita su poblamiento con colonos criollos y andinos. ${ }^{25}$ Ubicando a las naciones originarias en un rol subalterno en la nueva estructura social de las ciudades y pueblos que se iban formando.

También fue útil para reproducir un discurso civilizatorio en una región declarada como frontera abierta y con una ciudad próxima - el Cusco- que era la sede de una élite con cierto poder regional. Cuando termina el periodo estudiado en nuestro artículo, no sólo hay un giro en el seno de la iglesia católica sino también, una emergencia de fuerzas políticas en la región, que cuestionarán las bases y el legado construido en esa región: el aprismo y el comunismo. Estos partidos políticos elegirán ese territorio que tanto cos-

25 Esta ruta tuvo en forma resumida, cuatro pasos concurrentes y mutuamente influenciables: las exploraciones geográficas, la delimitación y defensa de las fronteras con Brasil y Bolivia, establecer nexos de comunicación y navegabilidad, y fomentar la inmigración colona. tó a hacendados y misioneros dominicos y pronto lo convertirán en un campo revolucionario: el valle de La Convención.

\section{Bibliografía}

Abarca, R. (2011). Trascendencia histórica de la migración al valle de Quillabamba y Cocabambilla entre 1750 y 1918. estudios amazónicos (9) enero-diciembre: 113-145.

Acosta, A (2014). «Religiosos, doctrinas y excedente económico indígena en el Perú a comienzos del siglo XVII» en Acosta, A. Prácticas Coloniales de la Iglesia en el Perú, siglos XVI-XVII: 127-16. Sevilla, Aconcagua,

Alberro, S. (1981). La actividad del Santo Oficio de la Inquisición en Nueva España 1571-1700. México, INAH.

Амiсн, J. (1988). Historia de las Misiones del Convento de Santa Rosa de Ocopa. Iquitos, CETA. (Edición crítica e introducción de Julián Heras).

BAER, G. (1994). Cosmología y chamanismo matsiguenga (Perú oriental). Quito: Abya-Yala.

Bataillon, M. (1976). Estudios sobre Bartolomé de las Casas. Barcelona: Península.

Bonfil, G. (1972). «El concepto de indio en América: un concepto colonial». Anales de Antropología (9): 105-124.

Brisseu, J. (1981). Le Cuzco Dans Sa Región. Etude d l' influence d'une ville andine. Bordeux/Lima, Centre de Etudes de Geographie Tropicale/Travux del IFEA XVI.

Castañeda, P. (1983). Las memorias del Padre Silva sobre la predicación pacifica y los Repartimientos. Colección Tierra nueva e cielo nuevo. Madrid, Consejo Superior de Investigaciones Científicas/Instituto Gonzalo Fernández de Oviedo.

Encinas, J. A. (1969). Ensayo de una escuela nueva en el Perú. Lima, Universo.

Esponera, A. y J. B. Lasségue (1991). El corte en la roca. Memorias de los dominicos en América (siglos XVI-XX). Cusco, Bartolomé de las Casas.

Fernández, W. (1952). Cincuenta años en la Selva Amazónica. Madrid, Juan Bravo.

FRY, C. (1889). La gran región de los bosques o ríos peruanos navegables: Urubamba, Ucayali, Amazonas, Pachitea y Palcazu. Diario de viajes y exploraciones, 1886, 1887 y 1888. Lima, Imprenta de Benito Gil. 
García, P. (1995). «Las misiones católicas en la Amazonia Peruana. Ocupación del territorio y control indígena (1821-1930)» en García, P. (coord.), La construcción de la Amazonia Andina (siglos XIX-XX). Quito, Abya-Yala.

García, P. (1998). Fronteras, colonización y mano de obra indígena en la Amazonía andina (siglos XIX-XX). Lima: Pontificia Universidad Católica del Perú (PUCP)/ Universitat de Barcelona.

Glave, L. M. (1980). «Problemas para el estudio de la historia regional: el caso del Cuzco». Allpanchis (16):131-164.

Hampe, T. (1997). «Cristianización y religiosidad en el Perú colonial». Anthropologica (15): 338-354.

Hermosa, W. (1986). Tribus selvicolas y misiones jesuitas y franciscanas en Bolivia. La Paz, Amigos del Libro.

Karsten, R (1955). Los Indios Shipibo del río Ucayali. Revista del Museo Nacional (24):154-173.

La Serna, J. C. (2012). Misiones, modernidad y civilización de los campas. Historia de la presencia adventista entre los asháninkas de la selva central peruana (19201948). Lima, Universidad Nacional Mayor de San Marcos (UNMSM).

Lopes de Carvalho, F. (2016). Estrategias de conversión y modos indígenas de apropiación del cristianismo en las misiones jesuíticas de Maynas. Anuario de Estudios Americanos (73) (1): 1638-1767.

Ludescher, M. (2000/2001). Instituciones y prácticas coloniales en la Amazonia peruana: pasado y presente. Indiana (17/18):313-359.

Marcone, J. (1999). Nuevos descubrimientos del Gran Río Amazonas: la «novela de la selva» y la crítica del imaginario de la Amazonia. Estudios. Julio-diciembre (8) 16.

MARZAL, M. (1983). La transformación religiosa peruana. Lima, Pontificia Universidad Católica del Perú (PUCP)

Marzal, Manuel (Coord.). (1991). El rostro indio de Dios. Lima, PUCP.

Marzal, M. y S. Negro (Coords.) (1999). Un reino en la frontera: misiones jesuitas en la América colonial, Lima: PUCP/Abya-Yala.

Morner, M. (1978). Perfil de la sociedad rural del Cuzco a fines de la colonia. Lima, Universidad del Pacífico.

Nalvarte, J. C. (2019). Representación de la guerra civil española por la prensa arequipeña (1936-1939).
HISTOreLO. Revista de historia regional y local 11 (21): 173-210.

Núńez, H. (2008). Presencia protestante en el altiplano peruano. Puno, 1898-1915. El caso de los Adventistas del Séptimo Día: actores y conflictos. Tesis de licenciatura en Antropología, Perú, UNMSM.

Palma, R. 1958[1897]. «Anales de la Inquisición de Lima» en Tradiciones Peruanas (IV): 295-387. Buenos Aires, Editorial Codex/Central Peruana de Publicaciones.

Pastor, B. (1983). El discurso narrativo de la conquista de América. La Habana, Casa de las Américas.

Pérez, I. (1986). Bartolomé de las Casas en el Perú, 15311573. Cusco, CBC.

Pérez, A. C. (2016). «Fotografías y Misiones: los informes de misión como performance civilizatorio». Maguare, 30 (1) enero-junio:103-139.

Pratt, M.L. (2010). Ojos imperiales. Literatura de viajes y transculturación. México, FCE.

Ramos, G. (Comp.) (1994). La venida del Reino. Religión, evangelización y cultura en América, siglos XVI-XX. Cusco, CBC.

Renard-Casevitz, M. F. (1988). "Geografía de algunos mitos y creencias: espacios simbólicos y realidades geográficas de los machiguenga del Alto-Urubamba». Amazonia Peruana (8) 16:17-40.

Richter, F. O.F. M. (1995). Presencia franciscana en el Perú en los siglos XVI al XX. Lima, Editorial Salesiana, 2 Vols.

Serra, I. (2018). «Los matsingenka y el legado pastoral, antropológico y cultural de los dominicos en el surperuano» en D. Pérez (Ed.) La Traducción en la Orden de los Predicadores, (2) Lengua, Lexicografía y Misión: 289-303. Granada: Comares.

SorIA, J. M. (1998). Entre tribus amazónicas. La aventura misionera del P. José Álvarez O.P. (1890-1970). Salamanca, San Esteban.

SaId, E. W. ( 2003). Orientalismo. Barcelona, Debolsillo.

TorD, L.E. (1978). El indio en los ensayistas peruanos 1848 1948. Lima: Editoriales Unidas.

VAn Kessel, J. (2008). Holocausto al progreso. Los aymaras de Tarapacá. Ámsterdam, CEDLA.

Vargas, R. (1951). Pareceres jurídicos en asuntos de Indias. Revista de Derecho de la Universidad Católica, s/f: 5-90.

Vidal, H. (1958). Visión del Cusco. Cusco, Garcilaso. 


\section{Imágenes}

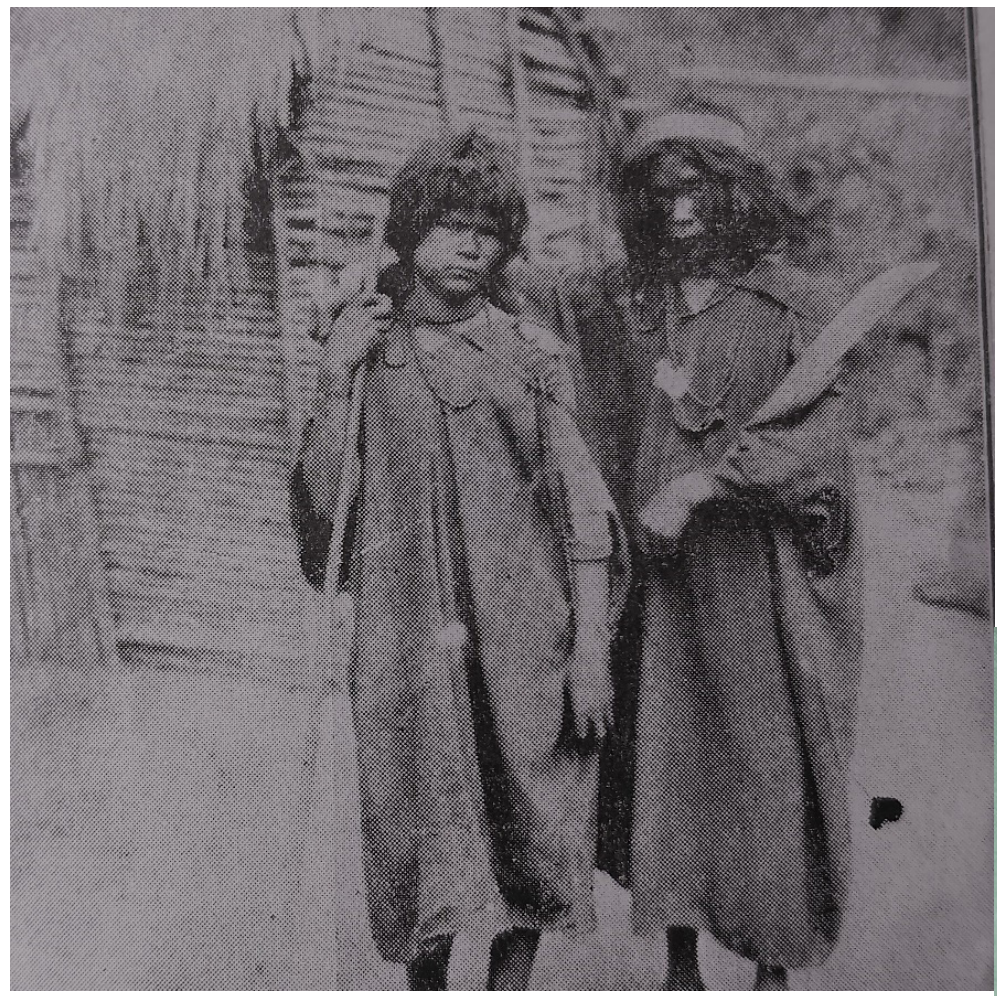

El pensamiento salvaje

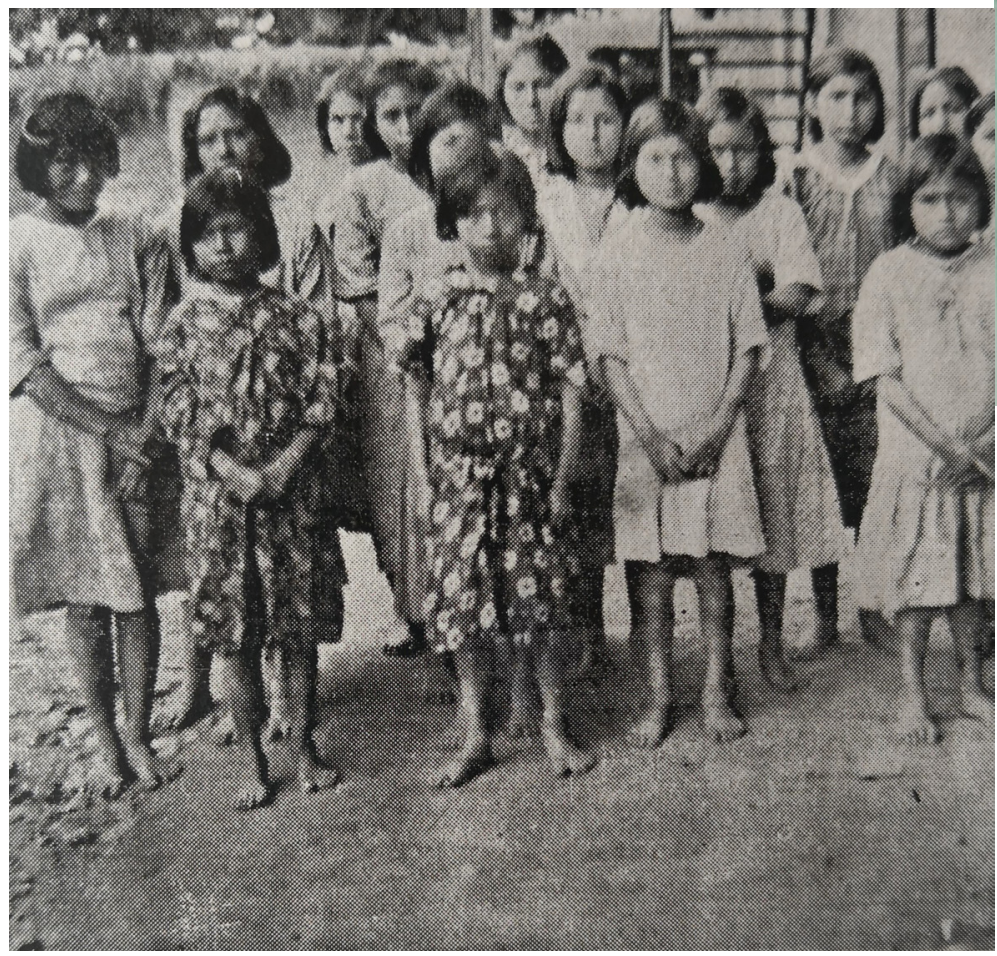

Niñas aculturadas 